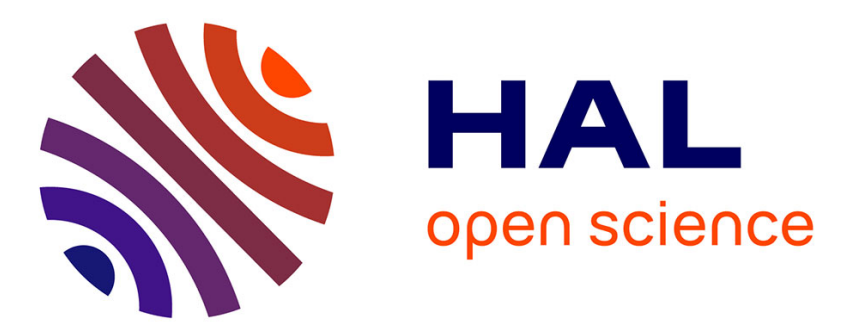

\title{
Second-Order Sliding Mode Control for DFIG-Based Wind Turbines Fault Ride-Through Capability Enhancement
}

Mohamed Benbouzid, Brice Beltran, Yassine Amirat, Gang Yao, Jingang Han, Hervé Mangel

\section{To cite this version:}

Mohamed Benbouzid, Brice Beltran, Yassine Amirat, Gang Yao, Jingang Han, et al.. Second-Order Sliding Mode Control for DFIG-Based Wind Turbines Fault Ride-Through Capability Enhancement. ISA Transactions, 2014, 53 (3), pp.827-833. hal-01020027

\section{HAL Id: hal-01020027 https://hal.science/hal-01020027}

Submitted on 7 Jul 2014

HAL is a multi-disciplinary open access archive for the deposit and dissemination of scientific research documents, whether they are published or not. The documents may come from teaching and research institutions in France or abroad, or from public or private research centers.
L'archive ouverte pluridisciplinaire HAL, est destinée au dépôt et à la diffusion de documents scientifiques de niveau recherche, publiés ou non, émanant des établissements d'enseignement et de recherche français ou étrangers, des laboratoires publics ou privés. 


\section{Second-Order Sliding Mode Control for DFIG-Based Wind Turbines Fault Ride-Through Capability Enhancement}

Mohamed Benbouzid, Brice Beltran, Yassine Amirat, Gang Yao, Jingang Han and Hervé Mangel

Abstract-This paper deals with the fault ride-through capability assessment of a doubly-fed induction generator-based wind turbine using a high-order sliding mode control. Indeed, it has been recently suggested that sliding mode control is a solution of choice to the fault ride-through problem. In this context, this paper proposes a second-order sliding mode as an improved solution that handle the classical sliding mode chattering problem. Indeed, the main and attractive features of high-order sliding modes are robustness against external disturbances, the grids faults in particular, and chattering-free behavior (no extra mechanical stress on the wind turbine drive train).

Simulations using the NREL FAST code on a 1.5-MW wind turbine are carried-out to evaluate ride-through performance of the proposed high-order sliding mode control strategy in case of grid frequency variations and unbalanced voltage sags.

Index Terms - Wind turbine, doubly-fed induction generator, fault-ride through, second-order sliding mode.

\footnotetext{
${ }^{1}$ University of Brest, EA 4325 LBMS, Rue de Kergoat, CS 93837, 29238 Brest Cedex 03, France

(e-mail: Mohamed.Benbouzid@univ-brest.fr, brice.beltran@dga.defense.gouv.fr, Herve.Mangel@univ-brest.fr).

${ }^{2}$ ISEN, EA 4325 LBMS, 20, Rue Cuirassé Bretagne, 29200 Brest, France

(e-mail: Yassine.Amirat@isen.fr).

${ }^{3}$ G. Yao and J. Han are with the Shanghai Maritime University, Department of Electrical Automation, 201306 Shanghai, China (email: gangyao@shmtu.edu.cn,jinganghan@shmtu.edu.cn).
} 


\section{Nomenclature}

$$
\begin{aligned}
& \text { WT = Wind Turbine; } \\
& \text { DFIG = Doubly-Fed Induction Generator; } \\
& \text { FRT = Fault Ride-Through; } \\
& \text { LVRT = Low-Voltage Ride-Through; } \\
& \text { HOSM = High-Order Sliding Mode; } \\
& \text { SOSM = Second-Order Sliding Mode; } \\
& \text { MPPT = Maximum Power Point Tracking; } \\
& v \quad=\text { Wind speed }(\mathrm{m} / \mathrm{sec}) \text {; } \\
& \rho \quad=\text { Air density }\left(\mathrm{kg} / \mathrm{m}^{3}\right) ; \\
& R=\text { Rotor radius }(\mathrm{m}) \text {; } \\
& P_{a} \quad=\text { Aerodynamic power }(\mathrm{W}) ; \\
& T_{a} \quad=\text { Aerodynamic torque }(\mathrm{Nm}) ; \\
& \lambda=\text { Tip speed ratio; } \\
& C_{p}(\lambda)=\text { Power coefficient; } \\
& \omega=\text { Wind turbine rotor speed }(\mathrm{rad} / \mathrm{sec}) ; \\
& T_{g} \quad=\text { Generator electromagnetic torque }(\mathrm{Nm}) \text {; } \\
& J \quad=\text { Turbine total inertia }\left(\mathrm{kg} \mathrm{m}^{2}\right) \text {; } \\
& K=\text { Turbine total external damping }(\mathrm{Nm} / \mathrm{rad} \mathrm{sec}) \text {; } \\
& d, q \quad=\text { Synchronous reference frame index; } \\
& s,(r)=\text { Stator (rotor) index; } \\
& V(I) \quad=\text { Voltage (Current); } \\
& P(Q) \quad=\text { Active (Reactive) power; } \\
& \phi \quad=\text { Flux; } \\
& T_{e m} \quad=\text { Electromagnetic torque; } \\
& R \quad=\text { Resistance; } \\
& L(M)=\text { Inductance (Mutual inductance); } \\
& \sigma \quad=\text { Leakage coefficient, } \sigma=1-M^{2} / L_{s} L_{r} ; \\
& \theta_{r} \quad=\text { Rotor position; } \\
& \omega_{r}\left(\omega_{s}\right)=\text { Angular speed (Synchronous speed); } \\
& s \quad=\text { Slip; } \\
& p \quad=\text { Pole pair number. }
\end{aligned}
$$




\section{Introduction}

An increasing number of power system operators have implemented technical standards known as grid codes that wind turbines must meet when connecting to the grid [1-2]. Generally, these grid codes requirements cover many topics such as, voltage operating range, power factor regulation, frequency operating range, grid support capability, and low fault ride-through capability. Indeed, grid codes dictate FRT requirements. LVRT capability is considered to be the biggest challenge in wind turbines design and manufacturing technology [3]. LVRT requires wind turbines to remain connected to the grid in presence of grid voltage sags.

The DFIG is one of the most frequently deployed large grid-connected wind turbines. Indeed, when compared with the full-scale power converter WT concept, the DFIG offers some advantages, such as reduced inverter and output filter costs due to low rotor- and grid-side power conversion ratings (25\%-30\%) [4]. However, DFIG-based WTs are very sensitive to grid disturbances, especially to voltage dips [5].

In this context, this paper proposes to address the FRT problems using a so-called active method achieving FRT with no additional devices. The goal is to control rotor voltages and currents, to reduce the rotor overvoltages and/or overcurrents, and therefore avoid the crowbar use/activation in order to keep full DFIG control at all times to meet the FRT requirements. The implementation of classical flux-oriented vector control techniques (PI controllers) has been proven to work well for the accomplishment of the initial grid code requirements [6-9]. But, this kind of control could be easily saturated when dealing with substantial sag. Moreover, it is sensitive to the generator parameters and other phenomena such as disturbances and unmodeled dynamics [10-11]. In particular, [10] gives a critical review of control methods for LVRT compliance with DFIG. This state-of-the-art review suggests the need of robust and nonlinear controller. A robust one have been proposed in [12], claiming full control in all LVRT cases. However, this was achieved with an oversized converter to accommodate rotor overvoltages and full rotor current control. It is therefore suggested that sliding mode control is a solution of choice to the FRT problem [13].

Therefore and in this particular context, this paper proposes the use of high-order sliding mode control as an improved solution that handles the classical sliding mode chattering problem and particularly avoids using additional devices and converter oversizing. Indeed, the main and attractive features of HOSMs are robustness against external disturbances (grid faults) and chattering-free behavior (no extra mechanical stress on the drive train) [14-16]. The proposed control strategy combines an MPPT using a second-order sliding mode for the DFIG control [17-18]. The proposed work is based on [17-18] philosophy (high-order sliding mode). In the case of [18], the control is on the turbine with a specific controller. In the case of [17], 
the control is on the DFIG as in this paper. However, this paper contribution is on the design of the secondorder sliding mode controller based on the supertwisting algorithm that takes into account grid disturbances, in addition to the optimal power extraction [19]. This strategy presents attractive features such as chatteringfree behavior, finite reaching time, robustness and unmodeled dynamics (generator and turbine). To check the overall control strategy ride-through performance, simulations using the NREL FAST code on a 1.5-MW wind turbine are carried-out in case of grid frequency variations and unbalanced voltage sags.

\section{Grid-Code Requirements}

Grid-code requirements typically refer to large wind farms connected to the transmission system, rather than smaller stations connected to the distribution network. These new grid codes stipulate that wind farms should contribute to power system control (frequency and also voltage), much as the conventional power stations, and emphasize wind farm behavior in case of abnormal operating conditions of the network (such as in case of voltage dips). The most common requirements include FRT capability, extended system voltage and frequency variation limits, active power regulation, and frequency control, as well as reactive power/power factor and voltage regulation capabilities [1-2]. Grid codes main requirements regarding the addressed faults are given below.

\subsection{Frequency Operating Range}

Wind power plants are required to run continuously within typical grid frequency variations between $49.5 \mathrm{~Hz}$ and $50.5 \mathrm{~Hz}$. Figure 1 gives an example of frequency-grid voltage variations [1].

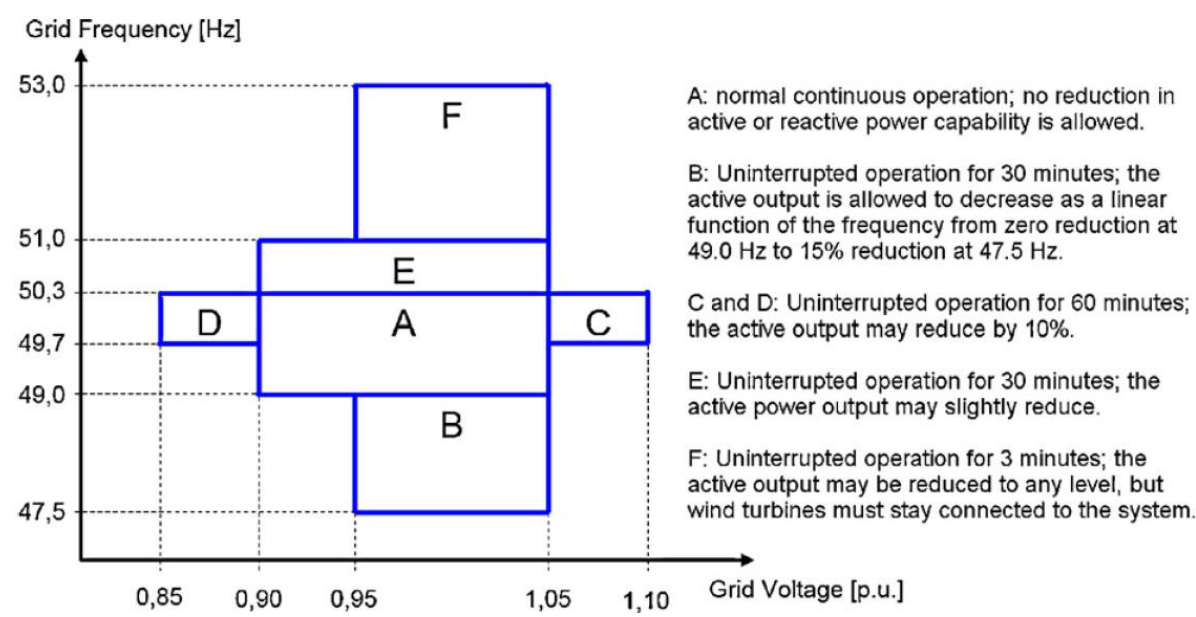

Fig. 1. Frequency-voltage variations ranges [@ Nordel] [1]. 


\subsection{Low Voltage Ride-Through}

Grid codes invariably require that large wind farms must withstand voltage sags down to a certain percentage of the nominal voltage and for a specified duration. Such constraints are known as LVRT requirements. They are described by a voltage versus time characteristic, denoting the minimum required immunity of the wind power station to the system voltage sags (Fig. 2) [1].

\section{Wind Turbine Modeling}

The wind turbine modeling is inspired from [17]. In the following, the wind turbine components models are briefly described.

\subsection{Turbine Model}

In this case, the aerodynamic power captured by the wind turbine is given by

$P_{a}=\frac{1}{2} \pi \rho R^{2} C_{p}(\lambda) v^{3}$

where $\lambda=\frac{R \omega}{v}$

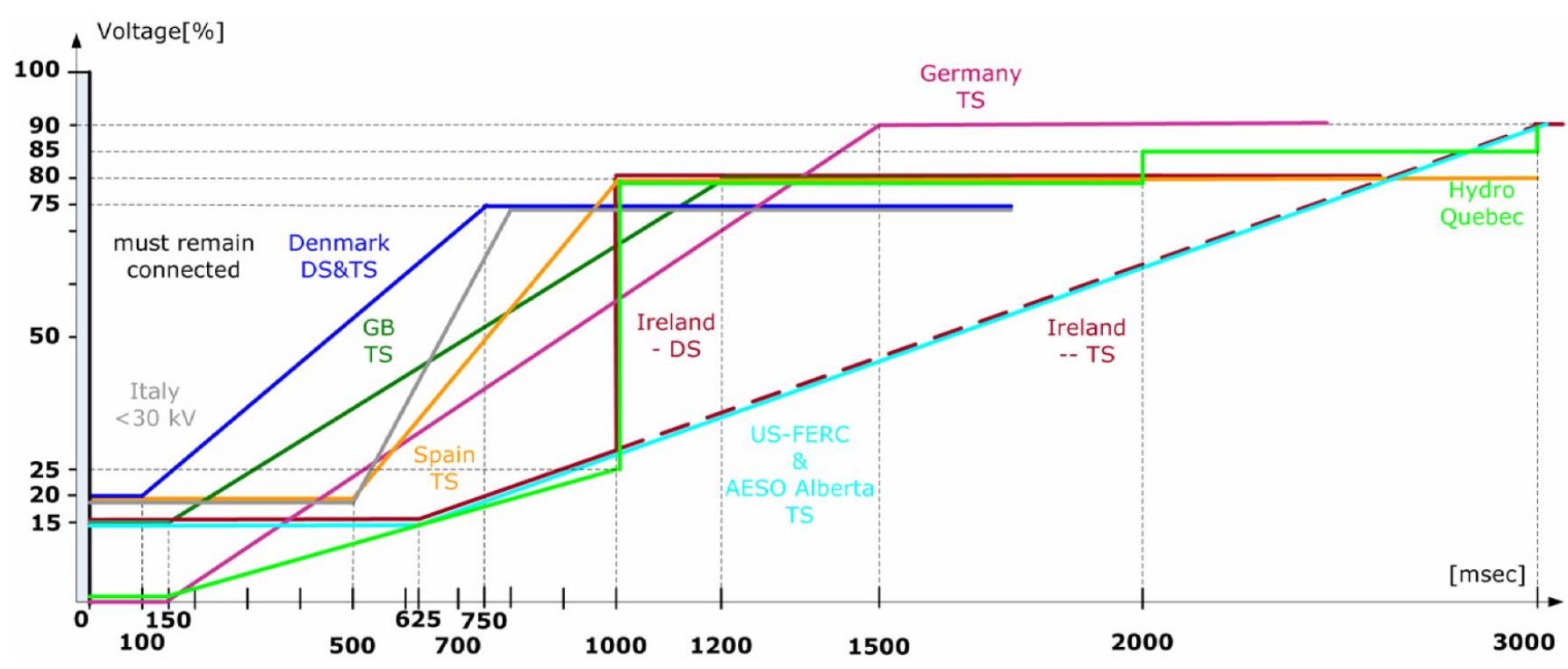

Fig. 2. LVRT requirements for different countries [1]. 
The rotor power (aerodynamic power) is also defined by

$$
P_{a}=\omega T_{a}
$$

The following simplified model is adopted for the turbine (drive train) for control purposes.

$$
J \dot{\omega}=T_{a}-K \omega-T_{g}
$$

\subsection{DFIG Model}

The control system is usually defined in the synchronous $d-q$ frame fixed to either the stator voltage or the stator flux. For the proposed control strategy, the generator dynamic model written in a synchronously rotating frame $d-q$ is given by

$$
\left\{\begin{array}{l}
V_{s d}=R_{s} I_{s d}+\frac{d \phi_{s d}}{d t}-\omega_{s} \phi_{s q} \\
V_{s q}=R_{s} I_{s q}+\frac{d \phi_{s q}}{d t}+\omega_{s} \phi_{s d} \\
V_{r d}=R_{r} I_{r d}+\frac{d \phi_{r d}}{d t}-\omega_{r} \phi_{r q} \\
V_{r q}=R_{r} I_{r q}+\frac{d \phi_{r q}}{d t}+\omega_{r} \phi_{r d} \\
\phi_{s d}=L_{s} I_{s d}+M I_{r d} \\
\phi_{s q}=L_{s} I_{s q}+M I_{r q} \\
\phi_{r d}=L_{r} I_{r d}+M I_{s d} \\
\phi_{r q}=L_{r} I_{r q}+M I_{s q} \\
T_{e m}=p M\left(I_{r d} I_{s q}-I_{r q} I_{s d}\right)
\end{array}\right.
$$

For simplification purposes, the $q$-axis is aligned with the stator voltage and the stator resistance is neglected. These will lead to

$$
\left\{\begin{array}{l}
\frac{d I_{r d}}{d t}=\frac{1}{\sigma L_{r}}\left(V_{r d}-R_{r} I_{r d}+s \omega_{s} \sigma L_{r} I_{r q}-\frac{M}{L_{s}} \frac{d \phi_{s d}}{d t}\right) \\
\frac{d I_{r q}}{d t}=\frac{1}{\sigma L_{r}}\left(V_{r q}-R_{r} I_{r q}-s \omega_{s} \sigma L_{r} I_{r d}-s \omega_{s} \frac{M}{L_{s}} \phi_{s d}\right) \\
T_{e m}=-p \frac{M}{L_{s}} \phi_{s d} I_{r q}
\end{array}\right.
$$




\section{DFIG-Based Wind Turbine Control}

\subsection{MPPT Strategy}

The control objective is to optimize the capture wind energy by tracking the optimal torque $T_{\text {opt }}$.

$T_{o p t}=k \omega^{2}$, with $k=\frac{1}{2} \pi \rho R^{5} \frac{C_{p \max }}{\lambda_{o p t}^{3}}$

Details about the adopted strategy are given in [17].

\subsection{HOSM Control Strategy}

The DFIG-based WT control objective is to optimize the extracted power by tracking the optimal torque $T_{o p t}$ (7). The control is a compromise between conversion efficiency and torque oscillation smoothing.

The reactive power is expressed as follows.

$Q_{s}=V_{s q} I_{s d}-V_{s d} I_{s q}$

Adapting (8) to our hypotheses, it comes then

$Q_{s}=\frac{V_{s} \phi_{s}}{L_{s}}-\frac{V_{s} M}{L_{s}} I_{r d}$

As the stator reactive power reference is zero, then

$\phi_{s}=\frac{V_{s}}{\omega_{s}} \rightarrow I_{r d_{-} r e f}=\frac{V_{s}}{\omega_{s} M}$

Let us consider the following tracking errors.

$\left\{\begin{array}{l}e_{I_{r d}}=I_{r d}-I_{r d_{-} r e f} \\ e_{T_{e m}}=T_{e m}-T_{r e f}\end{array}\right.$ 
Then we will have

$$
\left\{\begin{array}{l}
\dot{e}_{I_{r d}}=\frac{1}{\sigma L_{r}}\left(V_{r d}-R_{r} I_{r d}+g \omega_{s} L_{r} \sigma I_{r q}-\frac{M}{L_{s}} \frac{d \phi_{s d}}{d t}\right)-\dot{I}_{r d_{-} r e f} \\
\dot{e}_{T_{e m}}=-p \frac{M}{\sigma L_{s} L_{r}} \phi_{s}\left(\begin{array}{l}
\left.V_{r q}-R_{r} I_{r q}-g \omega_{s} L_{r} \sigma i_{r d}\right) \\
-g \omega_{s} \frac{M}{L_{s}} \phi_{s d}
\end{array}\right)-\dot{T}_{r e f}
\end{array}\right.
$$

If we define the $G_{1}$ and $G_{2}$ functions as follows.

$$
\left\{\begin{array}{l}
G_{1}=\frac{1}{\sigma L_{r}}\left(g \omega_{s} \sigma L_{r} I_{r q}-\frac{M}{L_{s}} \frac{d \phi_{s d}}{d t}\right)-\dot{I}_{r d_{-} r e f} \\
G_{2}=-p \frac{M}{\sigma L_{s} L_{r}} \phi_{s}\left(-g \omega_{s} \sigma L_{r} I_{r d}-g \omega_{s} \frac{M}{L_{s}} \phi_{s d}\right)-\dot{T}_{r e f}
\end{array}\right.
$$

Thus we have

$$
\left\{\begin{array}{l}
\ddot{e}_{I_{r d}}=\frac{1}{\sigma L_{r}} \dot{V}_{r d}+\dot{G}_{1}-\frac{1}{\sigma L_{r}} R_{r} \dot{I}_{r d} \\
\ddot{e}_{\Gamma_{e m}}=-p \frac{M}{\sigma L_{s} L_{r}} \phi_{s} \dot{V}_{r q}+\dot{G}_{2}+p \frac{M}{\sigma L_{s} L_{r}} \phi_{s} R_{r} \dot{I}_{r q}
\end{array}\right.
$$

Now, lets us consider the following second-order sliding mode controller based on the supertwisting algorithm [17-19].

$$
\left\{\begin{array}{l}
V_{r q}=y_{1}+B_{1}\left|e_{T_{e m}}\right|^{\frac{1}{2}} \operatorname{Sgn}\left(e_{T_{e m}}\right)+\frac{1}{\sigma L_{r}} R_{r} I_{r d} \\
\dot{y}_{1}=+B_{2} \operatorname{Sgn}\left(e_{T_{e m}}\right) \\
V_{r d}=y_{2}-B_{3}\left|e_{I_{r d}}\right|^{\frac{1}{2}} \operatorname{Sgn}\left(e_{I_{r d}}\right)-p \frac{M}{\sigma L_{s} L_{r}} \phi_{s} R_{r} I_{r q} \\
\dot{y}_{2}=-B_{4} \operatorname{Sgn}\left(e_{I_{r d}}\right)
\end{array}\right.
$$

Where $y_{1}$ and $y_{2}$ are intermediate variables and represent the control error integral.

To ensure the sliding manifolds convergence to zero in finite times, the gains $B_{1}, B_{2}, B_{3}$, and $B_{4}$ can be chosen as follows [19-20] 


$$
\left\{\begin{array}{l}
\left|\dot{G}_{1}\right|<\Phi_{1} \\
B_{1}>p \frac{M}{\sigma L_{s} L_{r}} \phi_{s} \Phi_{1}, B_{2}{ }^{2} \geq \frac{4 \Phi_{1}\left(B_{1}+\Phi_{1}\right)}{\sigma^{2} L_{r}{ }^{2}\left(B_{1}-\Phi_{1}\right)} \\
\left|\dot{G}_{2}\right|<\Phi_{2} \\
B_{3}>\frac{\Phi_{2}}{\sigma L_{r}}, B_{4}{ }^{2} \geq \frac{4 \Phi_{2}\left(B_{3}+\Phi_{2}\right)}{\sigma^{2} L_{r}{ }^{2}\left(B_{3}-\Phi_{2}\right)}
\end{array}\right.
$$

In this context, it can be asserted that there exist finite times $t_{\text {Tem }}$ and $t_{\text {Ird }}$ leading to (16). This means that the control objective is achieved.

$\begin{cases}I_{r d_{-} r e f}=I_{r d}, & \forall t>t_{I_{r d}} \\ T_{r e f}=T_{e m}, & \forall t>t_{T_{e m}}\end{cases}$

The above proposed second-order sliding mode control strategy for a DFIG-based WT is illustrated by Fig. 3.

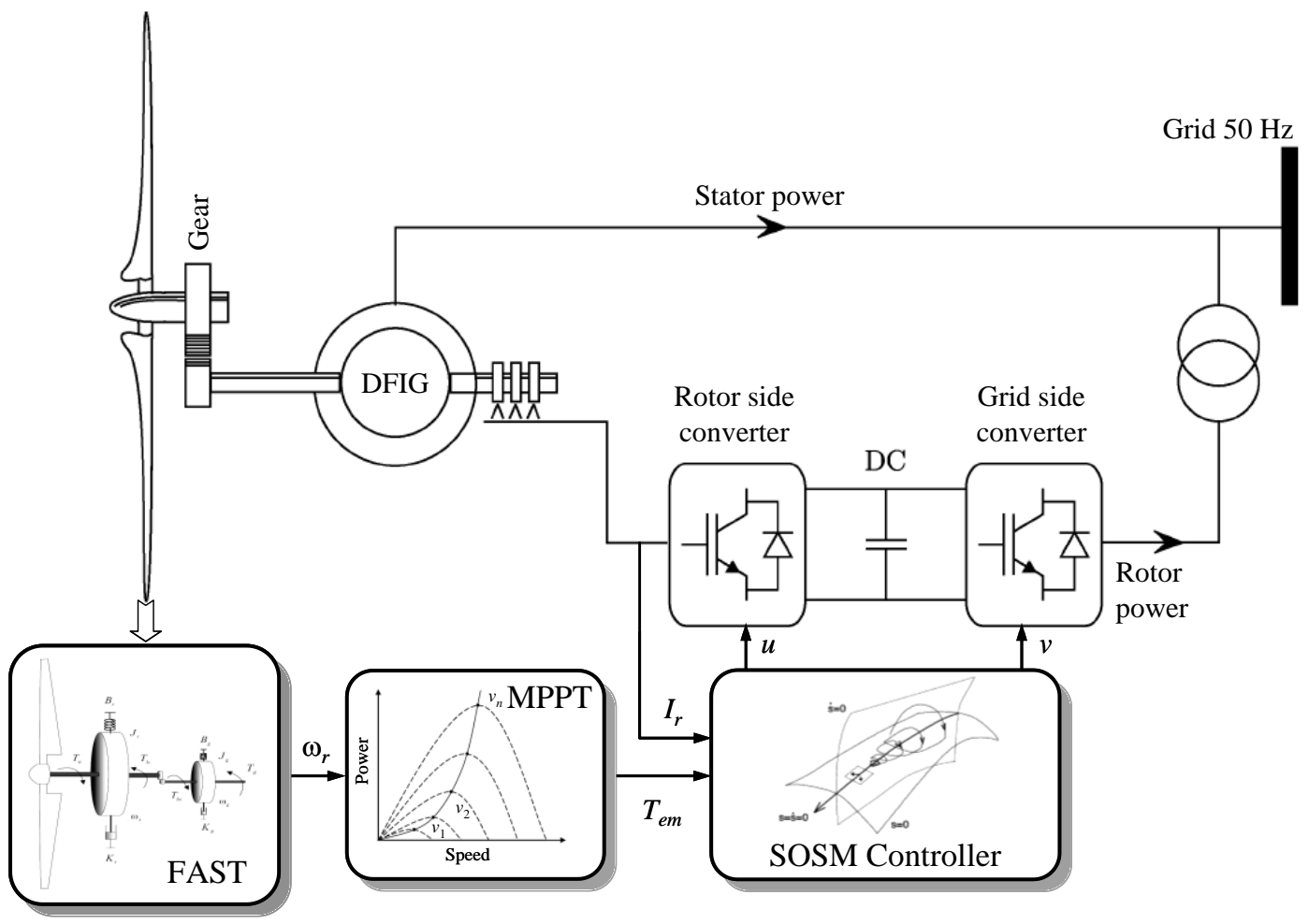

Fig. 3. The proposed FRT control structure. 


\section{Simulations using FAST Code}

Simulation using FAST with Matlab-Simulink ${ }^{\circledR}$ have been carried out on the NREL WP 1.5-MW wind turbine (Fig. 4) using turbulent FAST wind data shown by Fig. 5 [21]. The wind turbine, the DFIG ratings, and control parameters are given in the Appendix.

An interface has been developed between FAST and Matlab-Simulink ${ }^{\circledR}$ enabling users to implement advanced turbine controls in Simulink convenient block diagram form (Fig. 6). Hence, electrical model (DFIG, grid, control system, etc.) designed in the Simulink environment is simulated while making use of the complete nonlinear aerodynamic wind turbine motion equations available in FAST (Fig. 7).

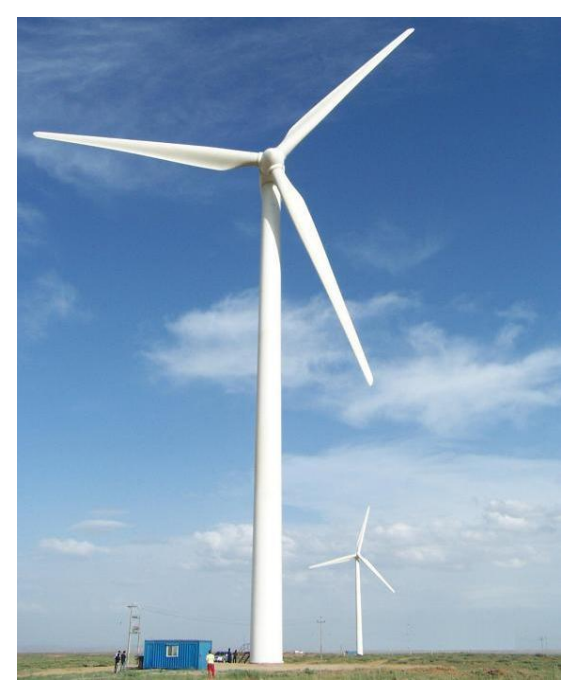

Fig. 4. 1.5-MW wind turbine illustration.

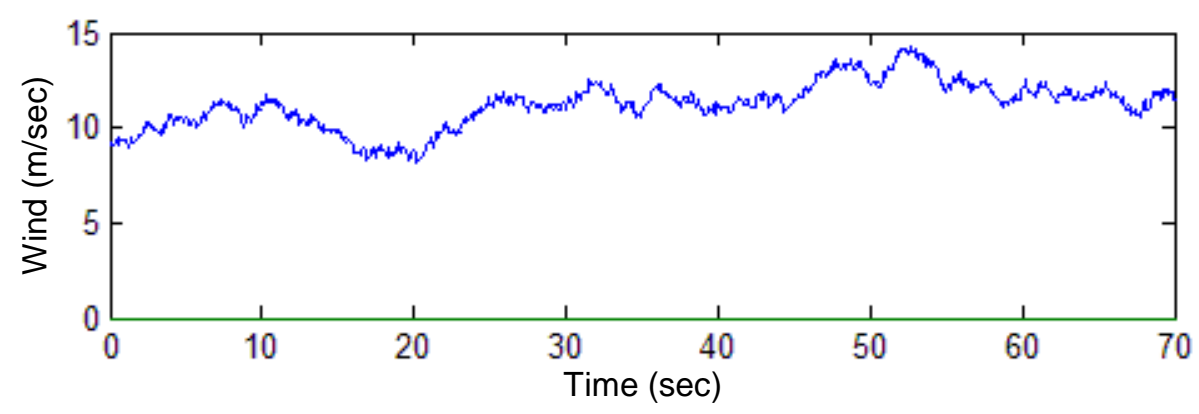

Fig. 5. Wind speed profile. 


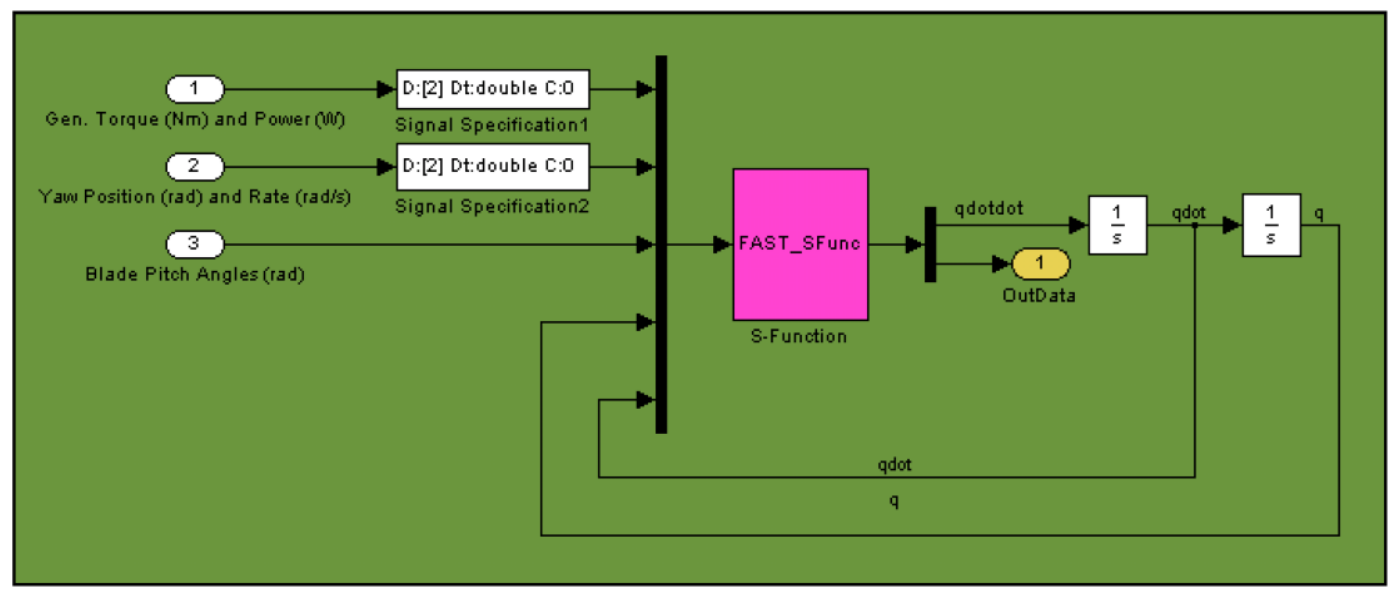

Fig. 6. FAST wind turbine block.

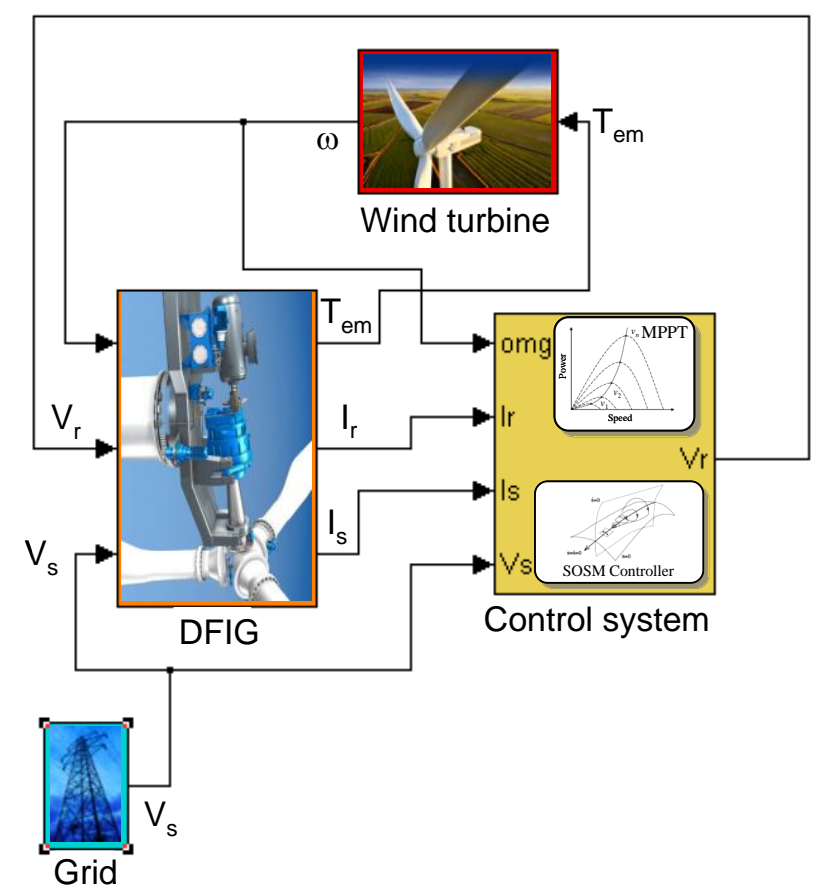

Fig. 7. Simulink model.

\subsection{Frequency Variation}

The proposed SOSM-based FRT strategy will be first tested regarding a frequency variation. Indeed, the studied case is a frequency fall from 50 to $48 \mathrm{~Hz}$ as illustrated by Fig. 8. This case corresponds to a power generation loss that could lead to a rapid decrease of the grid frequency. 


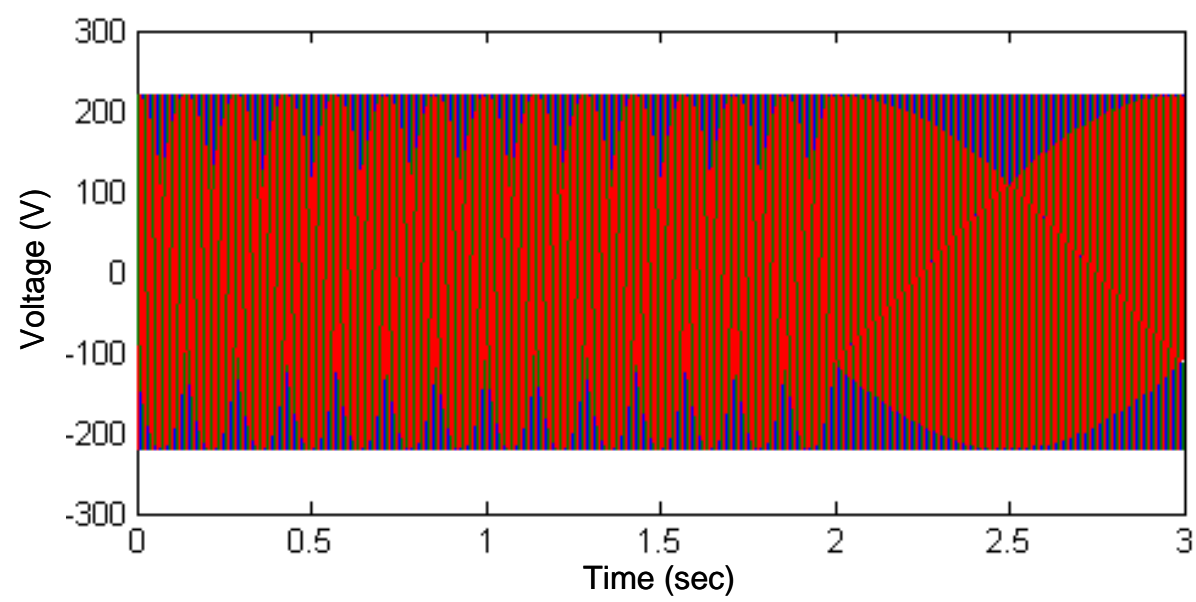

Fig. 8. Grid voltage.

The FRT performances are illustrated by Fig. 9. It clearly shows that the frequency fall has practically no effect on the torque. This is confirmed by the quadratic error shown by Fig. 10. Obviously, a good tolerance is achieved for this type of fault.

To assess the FRT capability enhancement of the proposed SOSM control approach, it has been compared to a classical PI control approach [22-23]. The achieved results as shown by Figs 11 and 12 clearly confirm the superiority of a high-order sliding mode approach over more classical control approaches. It should be noticed that the SOSM control approach achieves the same quadratic error as a classical first-order sliding mode control.

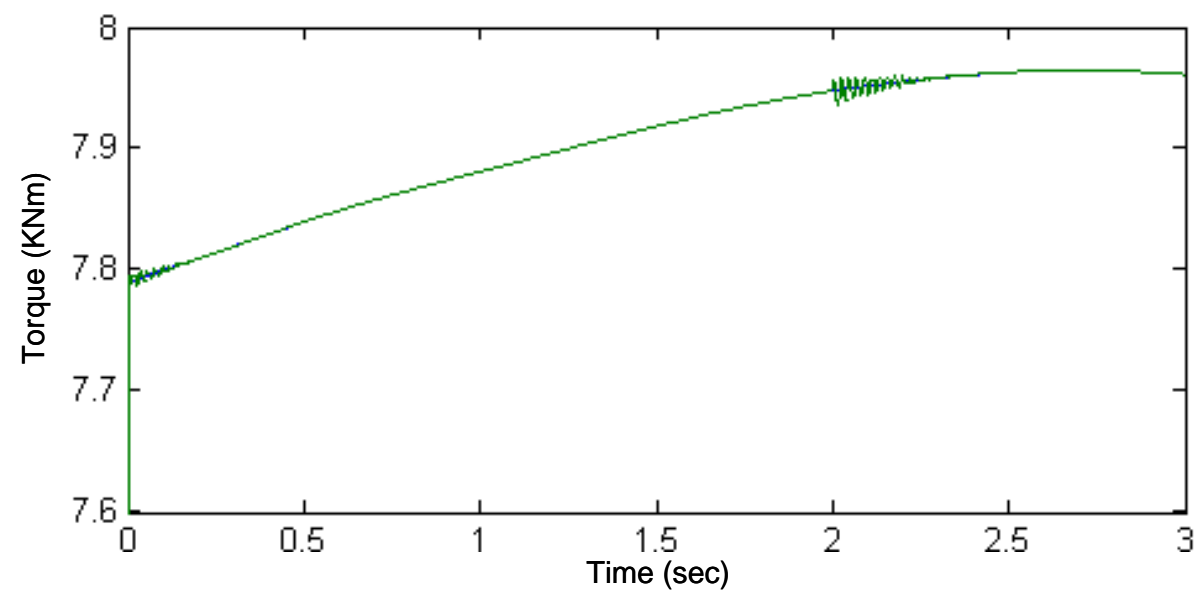

Fig. 9. Torque tracking performance during frequency variation: Reference (green) and real (blue). 


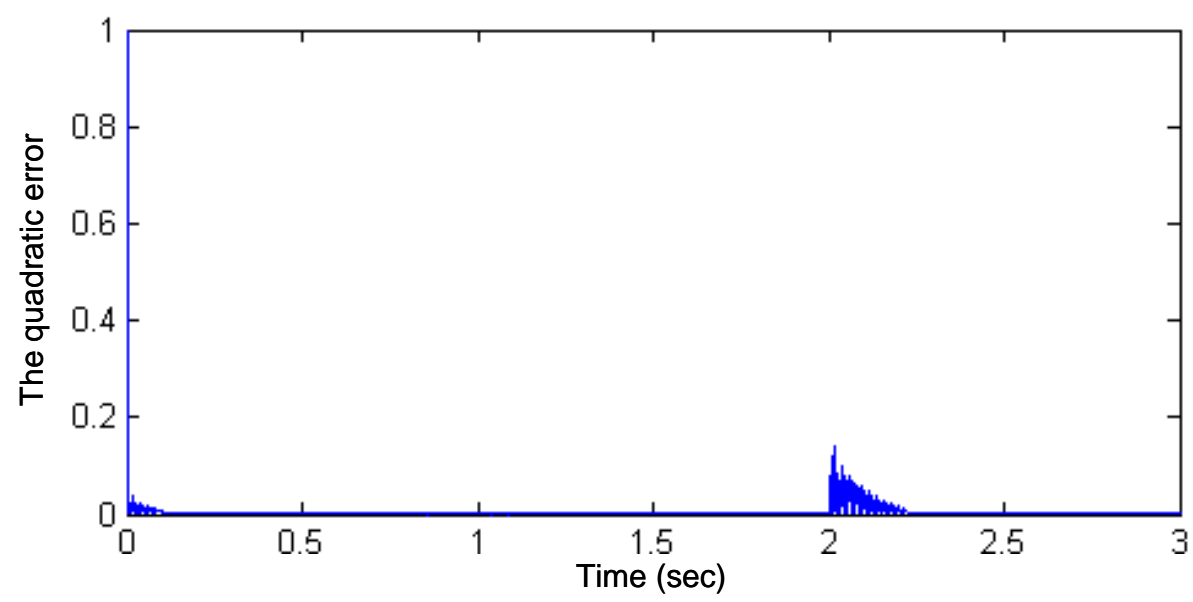

Fig. 10. Quadratic error between the reference torque and the SOSM control-based one (frequency variation).

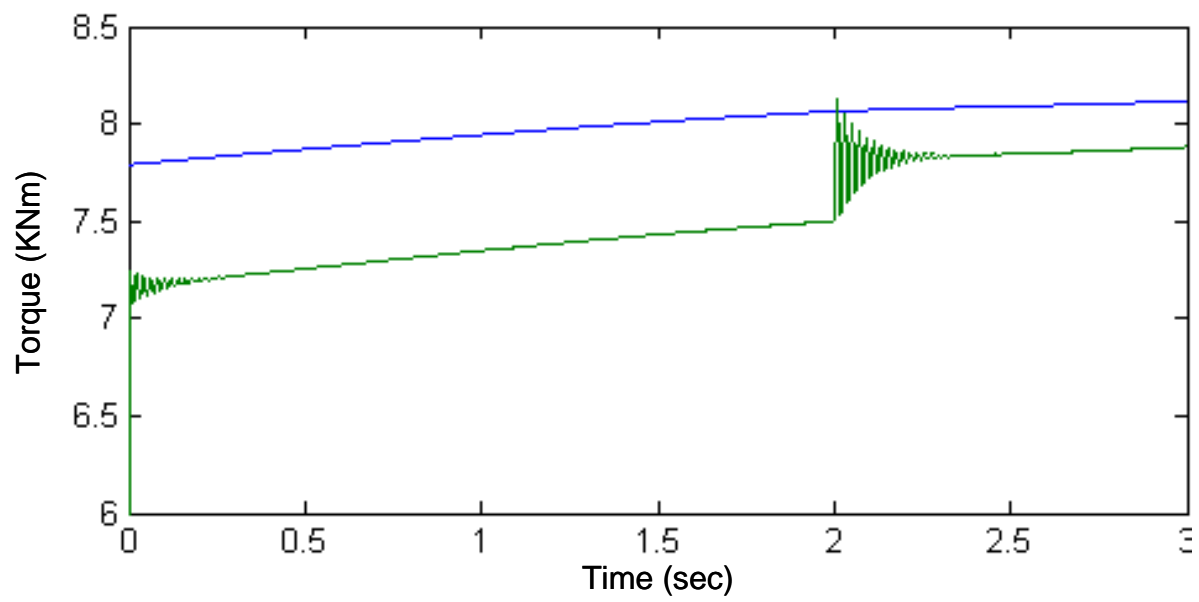

Fig. 11. Torque: Reference (green) and real (blue).

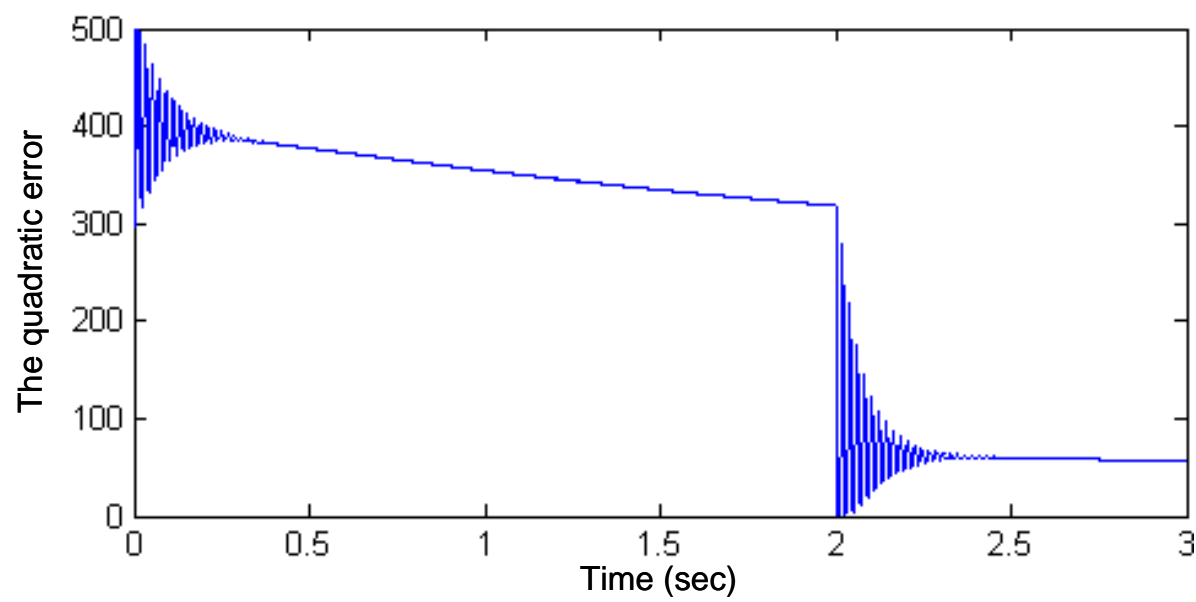

Fig. 12. Quadratic error between the reference torque and the PI control-based one (frequency variation). 


\subsection{Unbalanced Voltage Sags}

When unbalanced sags occur (Fig. 13), very high current, torque, and power oscillations appear at double of the electrical frequency, forcing a disconnection.

The LVRT performances are illustrated by Fig. 14 where an almost constant torque is achieved. Good tracking performances are also achieved in terms of DFIG rotor current (Fig. 15). Fault-tolerance performances are also confirmed by the quadratic error shown by Fig. 16.

To assess the LVRT capability enhancement of the proposed SOSM control approach, it has also been compared to the same classical PI control approach. The achieved results are illustrated by Fig. 17. This figure clearly shows that PI control achieves poorer LVRT performances.

If the FRT performances were similar in case of frequency variation, Fig. 18 shows the superiority of a high-order mode control over a first-one in case of unbalanced voltage sags.

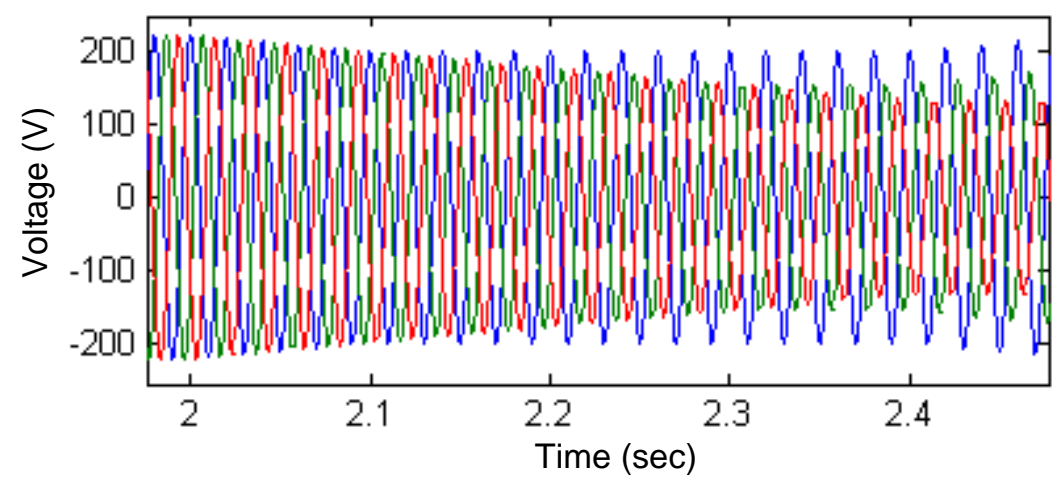

Fig. 13. Grid voltage.

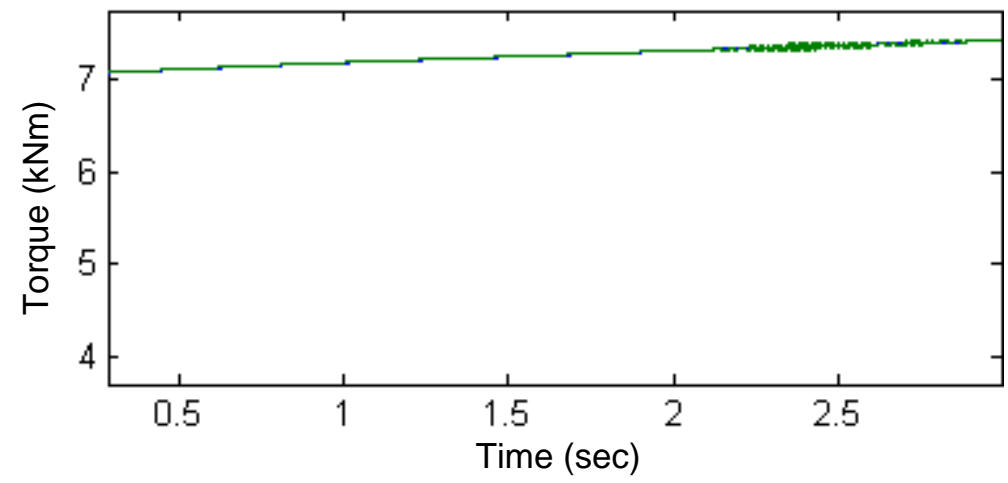

Fig. 14. Torque tracking performance during unbalanced voltage sags: Reference (blue) and real (green). 


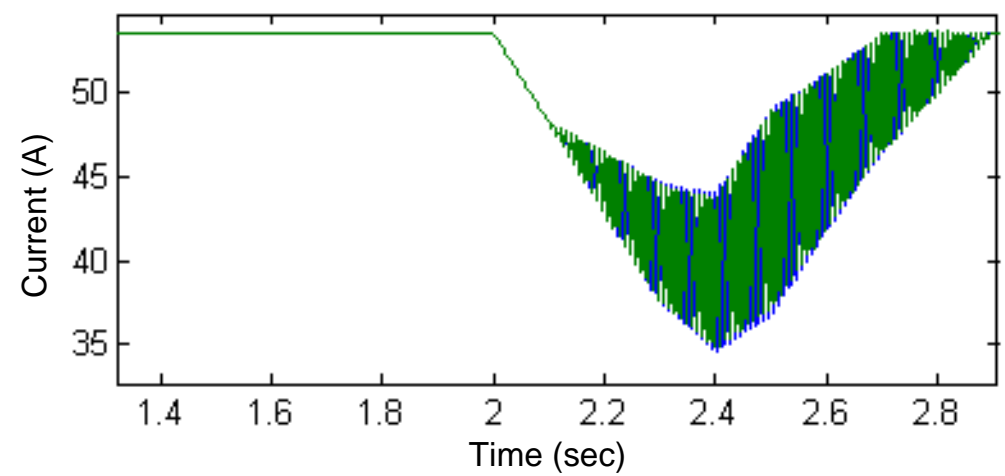

Fig. 15. Current $I_{r d}$ tracking performance during unbalanced voltage sags: Reference (blue) and real (green).

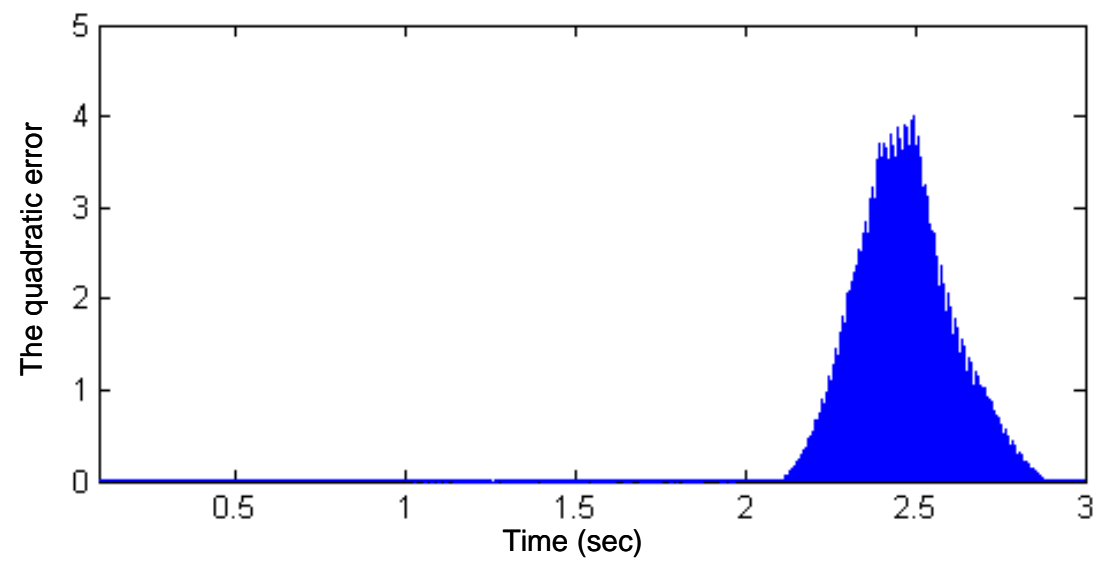

Fig. 16. Quadratic error between the reference torque and the SOSM control-based one (voltage sags).

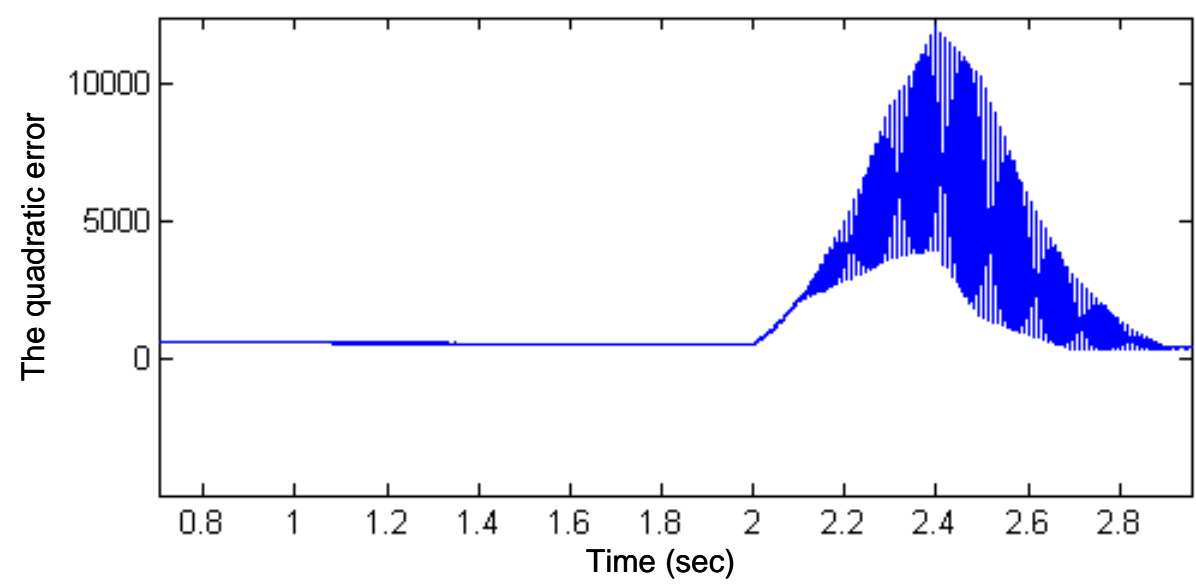

Fig. 17. Quadratic error between the reference torque and the PI control-based one (voltage sags). 


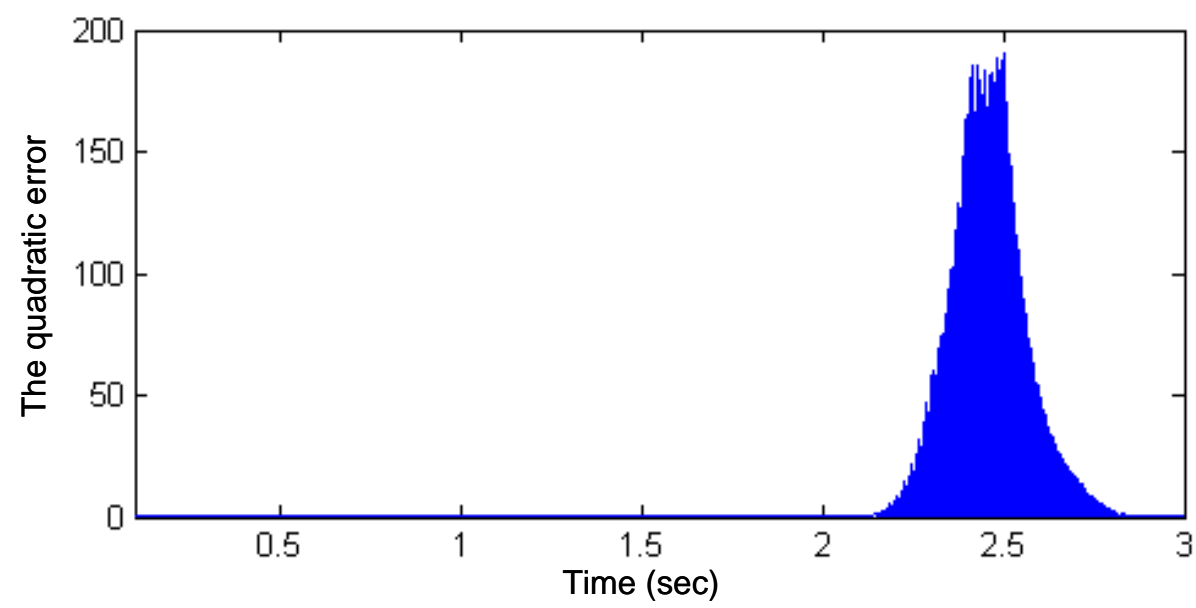

Fig. 18. Quadratic error between the reference torque and the first-order sliding mode control-based one (voltage sags).

\section{Conclusion}

This paper dealt with a second-order sliding mode control of a doubly-fed induction-based wind turbine for fault ride through. The SOSM-based FRT strategy has been tested regarding grid frequency variations and unbalanced voltage sags on a 1.5-MW three-blade wind turbine using the NREL wind turbine simulator FAST.

The achieved results show promising successful ride-through performances over well-known PI-based control and even over classical sliding mode control (first-order). It should be particularly mentioned that the proposed SOSM control approach does not need any specific adjustments to fault ride-through purposes.

\section{Appendix}

Simulated Wind Turbine Characteristics

\begin{tabular}{c|c}
\hline \hline Number of blades & 3 \\
\hline Rotor diameter & $70 \mathrm{~m}$ \\
\hline Hub height & $84.3 \mathrm{~m}$ \\
\hline Rated power & $1.5 \mathrm{MW}$ \\
\hline Turbine total inertia & $4.4532 \times 10^{5} \mathrm{~kg} \mathrm{~m}^{2}$ \\
\hline \hline
\end{tabular}




$$
R_{s}=0.005 \Omega, L_{s}=0.407 \mathrm{mH}, R_{r}=0.0089 \Omega, L_{r}=0.299 \mathrm{mH}, M=0.0016 \mathrm{mH}, p=2
$$

\section{Control Parameters}

$$
B_{1}=10, B_{2}=20000, B_{3}=7, B_{4}=500
$$

\section{References}

[1] M. Mohseni and S.M. Islam, "Review of international grid codes for wind power integration: Diversity, technology and a case for global standard," Renewable and Sustainable Energy Reviews, vol.16, n6, pp. 3876-3890, August 2012.

[2] M. Tsili and S. Papathanassiou, "A review of grid code technical requirements for wind farms," IET Renewable Power Generation, vol. 3, n³, pp. 308-332, September 2009.

[3] X. Yingcheng and T. Nengling, "Review of contribution to frequency control through variable speed wind turbine," Renewable Energy, vol. 36, n6, pp 1671-1677, June 2011.

[4] M. Liserre, R. Cardenas, M. Molinas and J. Rodriguez, "Overview of multi-MW wind turbines and wind parks,” IEEE Trans. Industrial Electronics, vol. 58, n4, pp. 1081-1095, April 2011.

[5] H.T. Jadhav and R. Roy, "A comprehensive review on the grid integration of doubly fed induction generator," International Journal of Electrical Power \& Energy Systems, vol. 49, pp. 8-18, July 2013.

[6] L. Yang, Z. Xu, J. Ostergaard, Z.Y. Dong and K.P. Wong, “Advanced control strategy of DFIG wind turbines for power system fault ride through," IEEE. Trans. Power Systems, vol. 27, n², pp. 713 722, May 2012.

[7] R. Abdelli, D. Rekioua, T. Rekioua and A. Tounzi, "Improved direct torque control of an induction generator used in a wind conversion system connected to the grid,” ISA Transactions, vol. 52, $\mathrm{n}^{\circ} 4$, pp. 525-538, July 2013.

[8] N. Khezami, N. Benhadj Braiek and X. Guillaud, "Wind turbine power tracking using an improved multimodel quadratic approach,” ISA Transactions, vol. 49, n³, pp. 326-334, July 2010.

[9] A.E. Leon, J.M. Mauricio and J.A. Solsona, "Fault ride-through enhancement of DFIG-based wind generation considering unbalanced and distorted conditions," IEEE. Trans. Energy Conversion, vol. 27, n³, pp. 775-783, September 2012. 
[10] R. Cardenas, R. Pena, S. Alepuz and G. Asher, "Overview of control systems for the operation of DFIGs in wind energy applications," IEEE Trans. Industrial Electronics, vol. 60, n7, pp. 2776-2798, July 2013.

[11] T. Long, S. Shao, C.Y. Li, Chun-Yin, E. Abdi and R.A. McMahon, "Crowbarless fault ride-through of the brushless doubly fed induction generator in a wind turbine under symmetrical voltage dips," IEEE Trans. Industrial Electronics, vol. 60, nº, pp. 2833-2841, July 2013.

[12] V.T. Phan and H.H. Lee, "Improved predictive current control for unbalanced stand-alone doubly-fed induction generator-based wind power systems," IET Electric Power Applications, vol. 5, n³, pp. 275-2875, 2011.

[13] M.I. Martinez, G. Tapia, A. Susperregui and H. Camblong, "Sliding-mode control for DFIG rotorand grid-side converters under unbalanced and harmonically distorted grid voltage," IEEE Trans. Energy Conversion, vol. 27, n², pp. 328-339, June 2012.

[14] I. Eker, "Second-order sliding mode control with experimental application," ISA Transactions, vol. 49, n³, pp. 394-405, July 2010.

[15] M.E.H. Benbouzid, B. Beltran, Y. Amirat, G. Yao, J. Han and H. Mangel, "High-order sliding mode control for DFIG-based wind turbine fault ride-through," in Proceedings of the 2013 IEEE IECON, Vienna (Austria), pp. 1-5, November 2013.

[16] M.E.H. Benbouzid, B. Beltran, M. Ezzat and S. Breton, "DFIG driven wind turbine grid faulttolerance using high-order sliding mode control," International Review on Modelling and Simulations, vol. 6, n¹, pp. 29-32, February 2013.

[17] B. Beltran, M.E.H. Benbouzid and T. Ahmed-Ali, "Second-order sliding mode control of a doubly fed induction generator driven wind turbine," IEEE Trans. Energy Conversion, vol. 27, n², pp. 261269, June 2012.

[18] B. Beltran, T. Ahmed-Ali and M.E.H. Benbouzid, "High-order sliding mode control of variable speed wind turbines," IEEE Trans. Industrial Electronics, vol. 56, n 9 , pp. 3314-3321, September 2009.

[19] A. Levant and L. Alelishvili, "Integral high-order sliding modes," IEEE Trans. Automatic Control, vol. 52, n 7, pp. 1278-1282, July 2007.

[20] H.K. Khalil, Nonlinear Systems. New York: McMillan, 1992, ch. 14.

[21] http://wind.nrel.gov/designcodes/simulators/fast/.

[22] J. $\mathrm{Hu}, \mathrm{H} . \mathrm{Xu}$ and $\mathrm{Y} . \mathrm{He}$, "Coordinated control of DFIG's RSC and GSC under generalized unbalanced and distorted grid voltage conditions," IEEE Trans. Industrial Electronics, vol. 60, n 7 , pp. 2808-2819, July 2013. 
[23] J. Hu, H. Xu and Y. He, "Integrated modeling and enhanced control of DFIG under unbalanced and distorted grid voltage conditions," IEEE Trans. Energy Conversion, vol. 27, n³, pp. 725-736, September 2012.

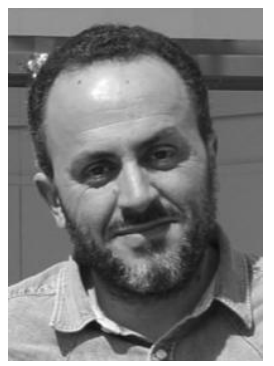

Mohamed El Hachemi Benbouzid was born in Batna, Algeria, in 1968. He received the B.Sc. degree in electrical engineering from the University of Batna, Batna, Algeria, in 1990, the M.Sc. and Ph.D. degrees in electrical and computer engineering from the National Polytechnic Institute of Grenoble, Grenoble, France, in 1991 and 1994, respectively, and the Habilitation à Diriger des Recherches degree from the University of Picardie "Jules Verne," Amiens, France, in 2000.

After receiving the Ph.D. degree, he joined the Professional Institute of Amiens, University of Picardie "Jules Verne," where he was an Associate Professor of electrical and computer engineering. Since September 2004, he has been with the Institut Universitaire de Technologie of Brest, University of Brest, Brest, France, where he is a Professor of electrical engineering. His main research interests and experience include analysis, design, and control of electric machines, variable-speed drives for traction, propulsion, and renewable energy applications, and fault diagnosis of electric machines.

Prof. Benbouzid is an IEEE Senior Member. He is the Editor-in-Chief of the International Journal on Energy Conversion (IRECON). He is also an Associate Editor of the IEEE TRANSACTIONS ON ENERGY CONVERSION, the IEEE TRANSACTIONS ON INDUSTRIAL ElECTRONICS, the IEEE TRANSACTIONS ON Sustainable Energy, and the IEEE Transactions on Vehicular Technology. He was an Associate Editor of the IEEE/ASME TRANSACTIONS ON MECHATRONICS from 2006 to 2009.

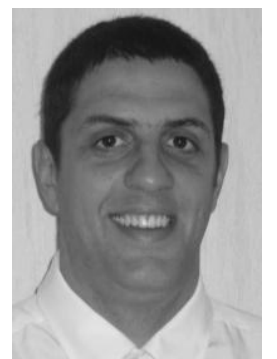

Brice Beltran was born in Arles, France, in 1981. He received the Engineer Degree in Electrical Engineering, from Ecole Nationale Supérieure d'Ingénieurs des Etudes et Techniques d'Armement (ENSIETA), Brest, France 2006, and the Ph.D. degree in Electrical Engineering in 2010 from the University of Brest, Brest, France.

In 2006, he joined the DGA (Délégation Générale pour 1'Armenent) as an Engineer and Technical Expert in information systems. In January 2010, he joined the LBMS Lab (EA 4325) as an Associate Member. His current research interests include modeling and control of renewable energy applications. 


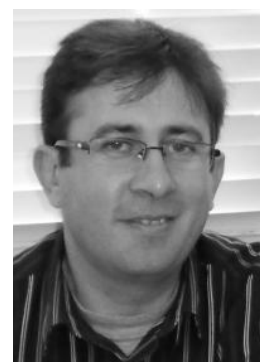

Yassine Amirat was born in Annaba, Algeria, in 1970. He received the B.Sc. and M.Sc. degrees both in electrical engineering, from the University of Annaba, Algeria, in 1994 and 1997 respectively. In 2011, he received the $\mathrm{PhD}$ degree in electrical engineering from the University of Brest, Brest, France.

Dr. Amirat was a Lecturer in the University of Annaba, Annaba, Algeria and than in the Institut Supérieur de l'Electronique et du Numérique (ISEN), Brest, France. Since January 2012, he is an Associate Professor of electrical engineering. His current research interests are the condition monitoring and the control of electrical drives and power electronics.

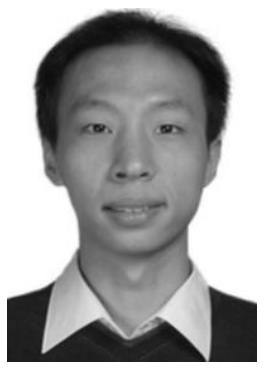

Gang Yao received his Ph.D. degree in electrical engineering from the Shanghai Maritime University, Shanghai, China, in 2008.

From 2008 to 2009, he was a post-doctoral research fellow at the Ecole Centrale de Nantes, Nantes, France. Since the end of 2009, he joined the Department of Electrical Automation of the Shanghai Maritime University, Shanghai, China, as an Associate Professor. His main research interests include intelligent information processing and intelligent control, fault diagnosis and fault-tolerant control of marine power systems and renewable energy generation systems.

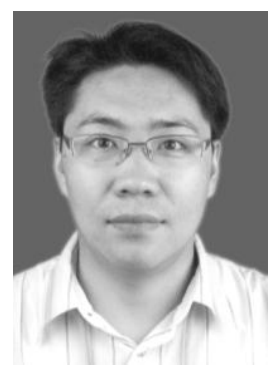

Jingang Han received the B. Eng. and Ph.D. degrees in electrical engineering from the Shanghai Maritime University, Shanghai, China, in 2001 and 2007, respectively.

Since 2007, he joined the Department of Electrical Automation of the Shanghai Maritime University, Shanghai, China, as an Associate Professor. From 2011 to 2012, he was a post-doctoral research fellow at the French Naval Academy, Brest, France. His research interests include analysis, design, and control of power converter, multilevel converter and renewable energy applications.

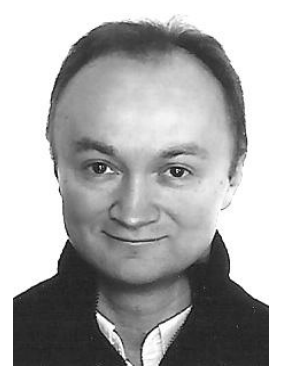

Hervé Mangel was born in Remiremont, France in 1969. He received the Ph.D. degree in electrical engineering from the University of Franche-Comté, Belfort, France in 1995.

From 1995 to 1997, he worked as a lecturer at the University of Franche-Comté, Belfort, France. From December 1997 to August 1998, he worked as Research Engineer for the European project High Voltage Booster in Railways (CEGELEC). Since 1998, he joined the University Institute of Technology (IUT) of Brest, University of Brest, Brest, France, as an 
Associate Professor of electrical engineering and a member of the LBMS Lab (EA 4325). His main research interests are in the field permanent magnet applications and electrical power generation applied in particular to renewable energies. 